Keywords: proteinuria; risk factors; angiogenesis inhibitors; VEGF inhibitors; sunitinib; pazopanib; metastatic renal cell carcinoma; survival

\title{
Risk factors of proteinuria in renal cell carcinoma patients treated with VEGF inhibitors: a secondary analysis of pooled clinical trial data
}

\author{
Michael J Sorich ${ }^{*}, 1,2$, Andrew Rowland ${ }^{1,2}$, Ganessan Kichenadasse ${ }^{2}$, Richard J Woodman ${ }^{3}$ \\ and Arduino A Mangoni ${ }^{1}$
}

${ }^{1}$ Department of Clinical Pharmacology, School of Medicine, Flinders University, Adelaide, South Australia 5042, Australia; ${ }^{2}$ Flinders Centre for Innovation in Cancer, School of Medicine, Flinders University, Adelaide, South Australia 5042, Australia and ${ }^{3}$ Flinders Centre for Epidemiology and Biostatistics, School of Medicine, Flinders University, Adelaide, South Australia 5042, Australia

Background: Proteinuria is a common adverse effect of vascular endothelial growth factor targeted agents, particularly in metastatic renal cell carcinoma (mRCC). However, risk factors for proteinuria are poorly defined.

Methods: Data on 1392 mRCC patients using pazopanib or sunitinib were pooled from two Phase-Ill clinical trials. Risk factors and prognostic effect of on-therapy proteinuria were evaluated by Cox proportional hazards regression.

Results: Any-grade (1-4) and grade 3/4 proteinuria incidence were $15.0 \%$ and 3.7\%, respectively. Asian ethnicity, diabetes, baseline systolic blood pressure (SBP), pre-existing grade 1 proteinuria and prior nephrectomy were significant independent predictors of either any-grade or grade 3/4 proteinuria. Proteinuria, particularly grade 3/4 (adjusted hazard ratio 0.53 (95\% confidence interval 0.30-0.92)), was associated with improved overall survival.

Conclusions: In mRCC patients using pazopanib or sunitinib, Asian ethnicity, diabetes, SBP, pre-existing proteinuria and prior nephrectomy were independent predictors of on-therapy proteinuria, which was associated with improved survival.

Anti-angiogenic agents targeting the vascular endothelial growth factor (VEGF) pathway have demonstrated efficacy for the treatment of a range of cancers, including metastatic renal cell carcinoma (mRCC). Proteinuria is a relatively common adverse effect of VEGF-targeted agents, particularly in mRCC (Zhu et al, 2007; Wu et al, 2010; Zhang et al, 2014), and its pathogenesis is likely multifactorial (Izzedine et al, 2013). It has been suggested that proteinuria may be a biomarker of clinical response to VEGFtargeted agents, but the evidence is currently inconclusive (Horsley et al, 2012).

Although risk factors for proteinuria in the general population (e.g., diabetes and hypertension) are well studied (Ramirez et al, 2002; Gross et al, 2005), they are poorly defined following use of
VEGF-targeted agents (Izzedine et al, 2010). A few small studies have identified baseline urine protein, estimated glomerular filtration rate (eGFR), diabetes and use of pamidronate as potential risk factors of proteinuria with VEGF-targeted therapy (Miller et al, 2005; Tomita et al, 2011; Feliu et al, 2015). In chronic kidney disease, the use of angiotensin system inhibitors (ASIs), angiotensin converting enzyme inhibitors or angiotensin receptor blockers has been shown to reduce the risk and progression of proteinuria. However, it is unknown whether use of ASIs may reduce the risk of proteinuria associated with VEGFtargeted therapies. Moreover, adverse event profiles for VEGFtargeted therapy appear to differ between Asian and non-Asian populations, although differences with respect to proteinuria have

*Correspondence: Dr M Sorich; E-mail: michael.sorich@flinders.edu.au 
not been specifically studied (Lee et al, 2014; Wang et al, 2014). This study primarily aimed to evaluate risk factors of proteinuria in a large cohort of patients with mRCC treated with either pazopanib or sunitinib.

\section{MATERIALS AND METHODS}

Study design and patients. The study was a pooled secondary analysis of patients with mRCC treated in two Phase-III randomised controlled trials: VEG105192 (NCT00334282, $n=435)$ comparing pazopanib to placebo, and COMPARZ (NCT00720941, $n=1110$ ) comparing pazopanib to sunitinib (Sternberg et al, 2010; Motzer et al, 2013). Anonymised patient level data was remotely accessed via a secure research environment following project approval by an independent review panel of the clinical trial data transparency portal clinicalstudydatarequest.com (reference number: 668; ClinicalTrials.gov Identifier: NCT02156310). The studies were approved by the institutional review board or ethics committee at each participating centre and all patients provided written informed consent (Sternberg et al, 2010; Motzer et al, 2013).

In brief, the studies enroled patients who are 18 years or older with mRCC involving a clear-cell histology component; whereas those with baseline grades $2-4$ proteinuria (urine protein to creatinine ratio $>0.3$ or urine protein dipstick $\geqslant 1+$, and $24-\mathrm{h}$ urine protein $>1 \mathrm{~g}$ ) among other criteria were excluded (Sternberg et al, 2010; Motzer et al, 2013).

Patient data and outcomes. Baseline covariates evaluated as risk factors for proteinuria were pre-existing grade 1 proteinuria (urine protein to creatinine ratio $>0.3$ or urine protein dipstick $\geqslant 1+$, but 24-h urine protein $<1 \mathrm{~g}$ ), age, sex, ethnicity, body surface area (BSA), baseline systolic blood pressure (SBP), history of diabetes (inferred from baseline use of medicines with ATC code A10A or A10B (Wright et al, 2011)), eGFR (Cockroft-Gault equation), prior nephrectomy, specific VEGF-targeted therapy, use of ASI, use of other antihypertensive drug classes (thiazide-like diuretics, betablockers and calcium channel blockers) and use of potentially nephrotoxic drug classes (non-steroidal anti-inflammatory drugs (NSAIDs), bisphosphonates).

The primary outcome evaluated was any-grade of on-therapy proteinuria based on the National Cancer Institute Common Terminology Criteria for Adverse Events v3.0, with grade 3/4 proteinuria (severe/life-threatening) as a secondary outcome. Assessment for proteinuria was generally performed mid-way and at the end of each 6-week cycle of sunitinib/pazopanib therapy.

Statistical analysis. Univariate and multivariable Cox proportional hazards regression was utilised to estimate the association between proteinuria and baseline covariates. Continuous variables were evaluated for non-linearity of association using restricted cubic splines with four knots. Multivariable Cox proportional hazards regression was used to evaluate the prognostic effect of proteinuria on overall survival (OS). The numerical grades of proteinuria (1-4) were included as a time-dependent covariate and was adjusted for pre-existing proteinuria (yes or no), duration of VEGF-targeted therapy, and established prognostic variables of mRCC survival (Heng et al, 2009). In addition, the effect of proteinuria occurring in the first two cycles (12 weeks) of therapy was evaluated.

Multiple imputation by chained equations $(n=20)$ was applied for analyses involving $>5 \%$ overall missing data, otherwise a complete case analysis was reported. All analyses were two-sided and undertaken using the $\mathrm{R}$ statistical environment version 3.0.2 (clinicalstudydatarequest.com.).

\section{RESULTS}

Baseline characteristics of the 1392 patients pooled from the two clinical studies are displayed in Table 1. On-therapy proteinuria of any-grade was reported for $203(15 \%)$ of patients, with grade 3/4 proteinuria reported for $52(3.7 \%)$ patients. Median time to anygrade and grade $3 / 4$ proteinuria was 32 and 100 days, respectively. Variables included in the analysis had $<4 \%$ missing data, with the exception of pre-existing proteinuria (10\%) and BSA (7\%).

Baseline predictors of any-grade proteinuria. In the multivariable analysis, individuals with pre-existing grade 1 proteinuria, Asian ethnicity, and higher SBP had significantly increased risk of any-grade on-therapy proteinuria (Table 2). Prior nephrectomy was associated with reduced risk of any-grade proteinuria. Notably, $30 \%$ of participants with an Asian ethnicity had on-therapy proteinuria compared with $8 \%$ of participants with white ethnicity (adjusted hazard ratio (HR) of 4.1, $P<0.001$ ). Diabetes, lower BSA and lower eGFR were associated with increased risk of proteinuria in univariate analysis, but were not statistically significant following adjustment for other covariates. Pazopanib had a trend towards increased risk of any-grade proteinuria compared with sunitinib (HR 1.31, $P=0.08$ ).

Baseline predictors of grade $3 / 4$ proteinuria. Pre-existing grade 1 proteinuria, Asian ethnicity and diabetes were identified as significant independent risk factors for on-therapy grade 3/4

\section{Table 1. Baseline characteristics of the study cohort}

\begin{tabular}{|c|c|}
\hline Variable & Mean \pm s.d., or $n(\%)$ \\
\hline Pre-existing proteinuria & $221(18)$ \\
\hline Age (years) & $60.1 \pm 10.8$ \\
\hline Male sex & $1005(72)$ \\
\hline $\begin{array}{l}\text { Ethnicity } \\
\text { White } \\
\text { Asian }{ }^{\mathrm{a}} \\
\text { Other }\end{array}$ & $\begin{array}{c}952(68) \\
414(30) \\
26(2)\end{array}$ \\
\hline SBP $(\mathrm{mm} \mathrm{Hg})$ & $126 \pm 13$ \\
\hline $\mathrm{DBP}(\mathrm{mm} \mathrm{Hg})$ & $75 \pm 8.9$ \\
\hline Heart rate & $78 \pm 12$ \\
\hline BSA $\left(m^{2}\right)$ & $1.91 \pm 0.27$ \\
\hline Diabetes & $178(13)$ \\
\hline eGFR $\left(m / \min ^{-1}\right)$ & $72 \pm 26$ \\
\hline Prior nephrectomy & $1179(85)$ \\
\hline $\begin{array}{l}\text { VEGF inhibitor allocated } \\
\text { Pazopanib } \\
\text { Sunitinib }\end{array}$ & $\begin{array}{l}844(61) \\
548(39)\end{array}$ \\
\hline Use of ASI & $350(26)$ \\
\hline $\begin{array}{l}\text { ACEI } \\
\text { ARB }\end{array}$ & $\begin{array}{l}223(16) \\
135(10)\end{array}$ \\
\hline Use of other AHD & $482(36)$ \\
\hline $\begin{array}{l}\text { CCB } \\
\text { Beta blocker } \\
\text { Thiazide diuretic }\end{array}$ & $\begin{array}{l}270(20) \\
234(17) \\
161(12)\end{array}$ \\
\hline Use of nephrotoxic drug & $342(25)$ \\
\hline $\begin{array}{l}\text { NSAID } \\
\text { Bisphosphonate }\end{array}$ & $\begin{array}{c}307(23) \\
61(4)\end{array}$ \\
\hline \multicolumn{2}{|c|}{$\begin{array}{l}\text { Abbreviations: } A C E I=\text { angiotensin converting enzyme inhibitor; } A H D=\text { antihypertensive } \\
\text { drug; } A R B=\text { angiotensin receptor blocker; } A S I=\text { angiotensin system inhibitor; } B S A=\text { body } \\
\text { surface area; } C C B=\text { calcium channel blocker; } D B P=\text { diastolic blood pressure; } \mathrm{GFRR}= \\
\text { estimated glomerular filtration rate; } N S A I D=\text { non-steroidal anti-inflammatory drug; } S B P= \\
\text { systolic blood pressure; VEGF: vascular endothelial growth factor. } \\
\text { a Predominantly East Asian or Japanese heritage. }\end{array}$} \\
\hline
\end{tabular}


Table 2. Association between baseline characteristics and on-therapy any-grade proteinuria

Unadjusted (univariate) analysis

Adjusted (multivariable) analysis

\begin{tabular}{|c|c|c|c|c|c|c|}
\hline & HR & $95 \% \mathrm{Cl}$ & $P$-value & HR & $95 \% \mathrm{Cl}$ & $P$-value \\
\hline Pre-existing proteinuria & 1.68 & $1.20-2.34$ & 0.003 & 1.65 & $1.17-2.33$ & 0.005 \\
\hline Age (per 10 years) & 1.03 & $0.90-1.17$ & 0.675 & 1.03 & $0.87-1.22$ & 0.711 \\
\hline Male sex & 1.09 & $0.79-1.50$ & 0.600 & 1.07 & $0.75-1.54$ & 0.702 \\
\hline $\begin{array}{l}\text { Ethnicity (vs White) } \\
\text { Asian } \\
\text { Other }\end{array}$ & $\begin{array}{l}4.13 \\
1.53\end{array}$ & $\begin{array}{l}3.08-5.54 \\
0.48-4.86\end{array}$ & $\begin{array}{r}<0.001 \\
0.471\end{array}$ & $\begin{array}{l}4.12 \\
1.45\end{array}$ & $\begin{array}{l}2.86-5.93 \\
0.45-4.63\end{array}$ & $\begin{array}{r}<0.001 \\
0.535\end{array}$ \\
\hline $\mathrm{SBP}($ per $10 \mathrm{~mm} \mathrm{Hg})$ & 1.06 & $0.96-1.18$ & 0.272 & 1.14 & $1.02-1.28$ & 0.025 \\
\hline BSA $\left(\right.$ per $\left.\mathrm{m}^{2}\right)$ & 0.23 & $0.13-0.40$ & $<0.001$ & 0.75 & $0.33-1.74$ & 0.507 \\
\hline Diabetes & 1.62 & $1.13-2.31$ & 0.009 & 1.45 & $0.98-2.14$ & 0.067 \\
\hline eGFR (per $10 \mathrm{ml} \mathrm{min}^{-1}$ ) & 0.94 & $0.89-0.99$ & 0.031 & 0.97 & $0.89-1.04$ & 0.372 \\
\hline Prior nephrectomy & 0.71 & $0.50-1.01$ & 0.060 & 0.67 & $0.46-0.98$ & 0.040 \\
\hline Pazopanib (vs sunitinib) & 1.31 & $0.97-1.78$ & 0.075 & 1.28 & $0.94-1.74$ & 0.112 \\
\hline Use of ASI & 0.80 & $0.57-1.11$ & 0.180 & 1.03 & $0.70-1.50$ & 0.897 \\
\hline Use of other AHD & 0.92 & $0.69-1.23$ & 0.578 & 0.97 & $0.69-1.36$ & 0.869 \\
\hline Use of nephrotoxic drug & 0.74 & $0.52-1.05$ & 0.091 & 0.93 & $0.64-1.34$ & 0.687 \\
\hline
\end{tabular}

Abbreviations: $\mathrm{AHD}=$ antihypertensive drug; $\mathrm{ASI}=$ angiotensin system inhibitor; $\mathrm{BSA}=$ body surface area; $\mathrm{Cl}=\mathrm{confidence}$ interval; eGFR=estimated glomerular filtration rate;

$\mathrm{HR}=$ hazard ratio; $\mathrm{SBP}=$ systolic blood pressure. Note: multiple imputation estimates reported for unadjusted pre-existing proteinuria and BSA, and all adjusted covariates.

Table 3. Association between baseline characteristics and on-therapy grade $3 / 4$ proteinuria

Unadjusted (univariate) analysis

Adjusted (multivariable) analysis

\begin{tabular}{|c|c|c|c|c|c|c|}
\hline & HR & $95 \% \mathrm{Cl}$ & $P$-value & HR & $95 \% \mathrm{Cl}$ & $P$-value \\
\hline Pre-existing proteinuria & 3.26 & $1.81-5.87$ & $<0.001$ & 3.04 & $1.65-5.61$ & 0.001 \\
\hline Age (per 10 years) & 1.21 & $0.92-1.58$ & 0.173 & 1.16 & $0.82-1.65$ & 0.400 \\
\hline Male sex & 0.99 & $0.53-1.86$ & 0.977 & 0.91 & $0.45-1.86$ & 0.796 \\
\hline $\begin{array}{l}\text { Ethnicity (vs White) } \\
\text { Asian } \\
\text { Other }\end{array}$ & $\begin{array}{l}2.35 \\
1.61\end{array}$ & $\begin{array}{l}1.34-4.11 \\
0.22-12.0\end{array}$ & $\begin{array}{l}0.003 \\
0.641\end{array}$ & $\begin{array}{l}3.34 \\
1.38\end{array}$ & $\begin{array}{l}1.60-6.95 \\
0.18-10.4\end{array}$ & $\begin{array}{l}0.001 \\
0.758\end{array}$ \\
\hline Diabetes & 3.24 & $1.78-5.91$ & $<0.001$ & 2.04 & $1.03-4.00$ & 0.040 \\
\hline eGFR (per $10 \mathrm{ml} \mathrm{min}^{-1}$ ) & 1.00 & $0.91-1.11$ & 0.957 & 1.07 & $0.93-1.22$ & 0.349 \\
\hline Prior nephrectomy & 0.67 & $0.34-1.34$ & 0.256 & 0.81 & $0.38-1.72$ & 0.588 \\
\hline Pazopanib (vs sunitinib) & 1.02 & $0.57-1.83$ & 0.942 & 0.98 & $0.54-1.79$ & 0.950 \\
\hline Use of ASI & 1.71 & $0.98-2.99$ & 0.061 & 1.48 & $0.75-2.91$ & 0.256 \\
\hline
\end{tabular}

proteinuria (Table 3). Individuals with pre-existing grade 1 proteinuria had an $8.1 \%$ risk of grade $3 / 4$ proteinuria, compared with $2.7 \%$ for individuals without pre-existing proteinuria (adjusted HR of 3.04, $P=0.001$ ). Individuals with Asian ethnicity had a $6.5 \%$ risk of grade $3 / 4$ proteinuria compared with $2.5 \%$ risk for individuals with white ethnicity (adjusted HR of 3.34, $P=0.001$ ). Individuals with diabetes had a $9.0 \%$ risk of grade $3 / 4$ proteinuria compared with $3.0 \%$ for individuals without diabetes (adjusted HR of 2.04, $P=0.04$ ). Use of non-ASI antihypertensive drugs was marginally statistically significant in univariate analysis, but not following adjustment for other covariates. No significant difference in risk of grade $3 / 4$ proteinuria was observed between pazopanib and sunitinib.

Dose modifications amongst Asian and White participants. Exploratory analysis indicated that Asian participants in the
COMPARZ study were more likely to have a dose modification (interruption or reduction) than White participants $(P=0.018$, Supplementary Table 1). Furthermore, dose modification due to proteinuria was more common for Asian participants than White participants $(P=0.001$, Supplementary Table 1$)$.

Association between proteinuria and overall survival. Over a median follow-up of 30 months, 690 (50\%) deaths were recorded. There was a statistically significant association between grade of proteinuria and OS (adjusted HR of 0.86 for each increase in grade, $P=0.015$ ). Notably, the adjusted OS HR was 0.53 (95\% CI 0.30 0.92 ) for grade $3 / 4$ proteinuria compared with no on-therapy proteinuria. Early proteinuria (first 12 weeks of therapy) had a trend towards association with improved OS (adjusted HR of 0.86 for each increase in grade, $P=0.053$ ). Median OS was 27.8 and 33.1 months, and was not reached within the study 
period, for patients without proteinuria in the first 12 weeks; those with grade $1 / 2$ proteinuria in the first 12 weeks; and those with grade $3 / 4$ proteinuria in the first 12 weeks, respectively (Supplementary Figure 1).

\section{DISCUSSION}

This study is the first to evaluate in detail the difference between Asian and White patients with respect to the risk of proteinuria during VEGF-targeted therapy. Clinical studies of Asian populations have raised the possibility that adverse event profiles may differ between Asian and non-Asian populations (Lee et al, 2014; Wang et al, 2014), but differences in proteinuria have not been studied specifically. It has been hypothesised that differences in BSA (particularly the smaller BSA in Asians) may partially explain these differences in trial adverse events (Zhou, 2012; Lee et al, 2014). In the current study, we observed that the risk of any-grade and grade $3 / 4$ proteinuria is increased for Asian patients, and that this difference is not explained by any of the other covariates assessed-including BSA. It has been speculated that differences in adverse events between Asian and non-Asian populations may be due to genetic differences (Kim et al, 2013).

This study also highlights that diabetes is independently associated with significantly higher incidence of on-therapy grade $3 / 4$ proteinuria. This is concordant with a study of 127 patients using bevacizumab for metastatic colorectal cancer (Feliu et al, 2015), and the well-established association between diabetes and proteinuria in the general population (Gross et al, 2005). SBP, a well-established risk factor for proteinuria and renal disease in the general population (Ramirez et al, 2002; Zemaitis et al, 2014), was also observed to be associated with increased risk of on-therapy proteinuria.

In addition, individuals with pre-existing grade 1 proteinuria were at significantly higher risk of any-grade and grade $3 / 4$ proteinuria which is concordant with results from a small study of Japanese patients using axitinib for mRCC (Tomita et al, 2011). In contrast to a prior study (Tomita et al, 2011), we did not find a significant association between baseline eGFR and on-therapy proteinuria. Although a significant unadjusted association between eGFR and any-grade proteinuria was observed, this was not significant following adjustment for other covariates.

There was no evidence that use of an ASI significantly reduced the risk of proteinuria following commencement of sunitinib/ pazopanib, or that use of NSAID or bisphosphonate drugs significantly increased the risk. The results of the current study were discordant with a prior study reporting that use of pamidronate (a bisphosphate drug) was associated with increased risk of proteinuria with bevacizumab treatment of metastatic breast cancer (Miller et al, 2005). The effects of ASIs and NSAIDs on proteinuria associated with VEGF-targeted therapy have not been previously reported. It is possible that the relationship is confounded by unmeasured variables that effect both the use of these medicines and the risk of proteinuria.

Proteinuria following commencement of sunitinib/pazopanib was associated with significantly improved OS. Specifically, the higher the grade of on-therapy proteinuria the better the survival outcome. Although this association has been studied previously, these studies have been limited by much smaller sample sizes (Horsley et al, 2012). The largest prior study included 169 patients with glioblastoma multiforme treated with bevacizumab and reported that proteinuria was independently associated with improved survival (Nangia et al, 2011). The second largest prior study included 127 patients with metastatic colorectal cancer treated with bevacizumab and found a significant association with improved response rate, but not OS (Feliu et al, 2015).
This association requires further validation, but it is possible that proteinuria is highlighting individuals with greater exposure or sensitivity to pazopanib/sunitinib A potential limitation of using proteinuria as a biomarker is that grade $3 / 4$ proteinuria often occurs relatively late after starting therapy (median time to onset of 100 days).

In conclusion, Asian ethnicity, diabetes, baseline SBP, pre-existing proteinuria and prior nephrectomy were predictors of proteinuria during sunitinib or pazopanib therapy for patients with mRCC. There was no evidence to indicate that baseline use of ASIs, other antihypertensive drugs, NSAIDs and bisphosphonates significantly altered the risk of proteinuria. Proteinuria was also observed to be a potential biomarker of improved survival following use of VEGF-targeted agents.

\section{CONFLICT OF INTEREST}

The authors declare no conflict of interest.

\section{REFERENCES}

Feliu J, Salud A, Safont MJ, García-Girón C, Aparicio J, Losa F, Bosch C, Escudero P, Casado E, Jorge M, Bohn U, Pérez-Carrión R, Carmona A, Custodio AB, Maurel J (2015) Correlation of hypertension and proteinuria with outcome in elderly bevacizumab-treated patients with metastatic colorectal cancer. PLoS One 10: e0116527.

Gross JL, de Azevedo MJ, Silveiro SP, Canani LH, Caramori ML, Zelmanovitz T (2005) Diabetic nephropathy: diagnosis, prevention, and treatment. Diabetes Care 28: 164-176.

Heng DYC, Xie W, Regan MM, Warren MA, Golshayan AR, Sahi C, Eigl BJ, Ruether JD, Cheng T, North S, Venner P, Knox JJ, Chi KN,

Kollmannsberger C, McDermott DF, Oh WK, Atkins MB, Bukowski RM, Rini BI, Choueiri TK (2009) Prognostic factors for overall survival in patients with metastatic renal cell carcinoma treated with vascular endothelial growth factor-targeted agents: results from a large, multicenter study. J Clin Oncol 27: 5794-5799.

Horsley L, Marti K, Jayson GC (2012) Is the toxicity of anti-angiogenic drugs predictive of outcome? A review of hypertension and proteinuria as biomarkers of response to anti-angiogenic therapy. Expert Opin Drug Metab Toxicol 8: 283-293.

Izzedine H, Massard C, Spano JP, Goldwasser F, Khayat D, Soria JC (2010) VEGF signalling inhibition-induced proteinuria: Mechanisms, significance and management. Eur J Cancer 46: 439-448.

Izzedine H, Soria JC, Escudier B (2013) Proteinuria and VEGF-targeted therapies: an underestimated toxicity? J Nephrol 26: 807-810.

Kim HR, Park HS, Kwon WS, Lee JH, Tanigawara Y, Lim SM, Kim HS, Shin SJ, Ahn JB, Rha SY (2013) Pharmacogenetic determinants associated with sunitinib-induced toxicity and ethnic difference in Korean metastatic renal cell carcinoma patients. Cancer Chemother Pharmacol 72: 825-835.

Lee S-H, Bang Y-J, Mainwaring P, Ng C, Chang JWC, Kwong P, Li RK, Sriuranpong V, Toh C-K, Yuan J, Pitman Lowenthal S, Chung HC (2014) Sunitinib in metastatic renal cell carcinoma: an ethnic Asian subpopulation analysis for safety and efficacy. Asia Pac J Clin Oncol 10: 237-245.

Miller KD, Chap LI, Holmes FA, Cobleigh MA, Marcom PK, Fehrenbacher L, Dickler M, Overmoyer BA, Reimann JD, Sing AP, Langmuir V, Rugo HS (2005) Randomized phase III trial of capecitabine compared with bevacizumab plus capecitabine in patients with previously treated metastatic breast cancer. J Clin Oncol 23: 792-799.

Motzer RJ, Hutson TE, Cella D, Reeves J, Hawkins R, Guo J, Nathan P, Staehler M, de Souza P, Merchan JR, Boleti E, Fife K, Jin J, Jones R, Uemura H, De Giorgi U, Harmenberg U, Wang J, Sternberg CN, Deen K, McCann L, Hackshaw MD, Crescenzo R, Pandite LN, Choueiri TK (2013) Pazopanib versus sunitinib in metastatic renal-cell carcinoma. $N$ Engl J Med 369: 722-731.

Nangia CS, Wang D, Scarpace L, Schultz L, Khanshour A, Mikkelsen T (2011) The role of the development of hypertension or proteinuria in predicting outcome with the use of bevacizumab for patients with glioblastoma multiforme (GBM). ASCO Meeting Abstracts e2021. 
Ramirez SP, McClellan W, Port FK, Hsu SI (2002) Risk factors for proteinuria in a large, multiracial, southeast Asian population. J Am Soc Nephrol 13: 1907-1917.

Sternberg CN, Davis ID, Mardiak J, Szczylik C, Lee E, Wagstaff J, Barrios CH, Salman P, Gladkov OA, Kavina A, Zarbá JJ, Chen M, McCann L, Pandite L, Roychowdhury DF, Hawkins RE (2010) Pazopanib in locally advanced or metastatic renal cell carcinoma: results of a randomized phase III trial. J Clin Oncol 28: 1061-1068.

Tomita Y, Uemura H, Fujimoto H, Kanayama H-o, Shinohara N, Nakazawa H, Imai K, Umeyama Y, Ozono S, Naito S, Akaza H (2011) Key predictive factors of axitinib (AG-013736)-induced proteinuria and efficacy: A phase II study in Japanese patients with cytokine-refractory metastatic renal cell Carcinoma. Eur J Cancer 47: 2592-2602.

Wang Y, Choueiri TK, Lee JL, Tan MH, Rha SY, North SA, Kollmannsberger CK, McDermott DF, Heng DYC (2014) Anti-VEGF therapy in mRCC: differences between Asian and non-Asian patients. Br J Cancer 110: $1433-1437$.

Wright A, Pang J, Feblowitz JC, Maloney FL, Wilcox AR, Ramelson HZ, Schneider LI, Bates DW (2011) A method and knowledge base for automated inference of patient problems from structured data in an electronic medical record. J Am Med Inform Assoc 18: 859-867.

Wu S, Kim C, Baer L, Zhu X (2010) Bevacizumab increases risk for severe proteinuria in cancer patients. J Am Soc Nephrol 21: 1381-1389.
Zemaitis P, Liu K, Jacobs Jr DR, Cushman M, Durazo-Arvizu R, Shoham D, Palmas W, Cooper R, Kramer H (2014) Cumulative systolic BP and changes in urine albumin-to-creatinine ratios in nondiabetic participants of the multi-ethnic study of atherosclerosis. Clin J Am Soc Nephrol 9: 1922-1929.

Zhang Z-F, Wang T, Liu L-H, Guo H-Q (2014) Risks of proteinuria associated with vascular endothelial growth factor receptor tyrosine kinase inhibitors in cancer patients: a systematic review and meta-analysis. PLoS One 9: e90135.

Zhou A (2012) Management of sunitinib adverse events in renal cell carcinoma patients: the Asian experience. Asia Pac J Clin Oncol 8: 132-144.

Zhu X, Wu S, Dahut WL, Parikh CR (2007) Risks of proteinuria and hypertension with bevacizumab, an antibody against vascular endothelial growth factor: systematic review and meta-analysis. Am J Kidney Dis 49: 186-193.

This work is published under the standard license to publish agreement. After 12 months the work will become freely available and the license terms will switch to a Creative Commons AttributionNonCommercial-Share Alike 4.0 Unported License.

Supplementary Information accompanies this paper on British Journal of Cancer website (http://www.nature.com/bjc) 